\title{
Um modelo de otimização para alíquotas do IPTU socialmente mais justas ${ }^{1}$
}

\author{
José Delfino Sá \\ Universidade do Estado da Bahia \\ Carlos Arthur Mattos Teixeira Cavalcante \\ Universidade Federal da Bahia \\ Ricardo de Araújo Kalid \\ Universidade Federal da Bahia \\ Ulisses de Araújo Malveira \\ Secretaria da Fazenda da Prefeitura Municipal de Salvador
}

\begin{abstract}
Este artigo apresenta um modelo de otimização matemática não linear que determina novas alíquotas para o Imposto sobre a Propriedade Predial e Territorial Urbana (IPTU) incidente sobre os apartamentos residenciais no município do Salvador (BA). São considerados a progressividade das alíquotas, os valores venais dos imóveis, as rendas médias dos contribuintes e as usuais metodologias de cálculo do valor do imposto. Os resultados obtidos na aplicação desse modelo demonstram ser possível tratar de forma objetiva e socialmente mais justa a definição das alíquotas de IPTU para todos os tipos de imóveis de um município.
\end{abstract}

Palavras-chave: Imposto sobre a Propriedade Predial e Territorial Urbana (IPTU); finanças públicas; justiça tributária; pesquisa operacional; modelagem com programação não linear.

Un modelo de optimización de las tasas de impuestos a la propiedad socialmente más justo En este trabajo se presenta un modelo de optimización matemática no lineal que determinan las nuevas tarifas del Impuesto Inmobiliario Urbano - Impuesto sobre la propiedad aplicado en apartamentos residenciales en la ciudad de Salvador (BA). Ellos se consideran la progresividad de los tipos impositivos, el mercado de valores de las propiedades, los ingresos medios de los contribuyentes y de los métodos habituales de cálculo de la cuantía del impuesto. Los resultados demuestran que la aplicación de este

\footnotetext{
Artigo recebido em 12 set. 2011 e aceito em 5 out. 2012.

${ }^{1}$ As pesquisas e o estudo que resultaram nos modelos apresentados neste artigo foram possibilitados pela parceria entre a Escola Politécnica da Universidade Federal da Bahia (Ufba) e a Secretaria da Fazenda da Prefeitura Municipal de Salvador, fazendo parte do projeto de pesquisa para uma tese de doutorado do Programa de Engenharia Industrial daquela universidade, com o foco principal em uma nova modelagem para o processo do Imposto sobre a Propriedade Predial e Territorial Urbana (IPTU) de Salvador que estimule o desenvolvimento sustentável do município.
} 
modelo se puede tratar de manera objetiva y socialmente más justo fijar los tipos de impuestos a la propiedad para todos los tipos de propiedades en un municipio.

Palabras clave: Impuesto sobre Terrenos Urbanos y Propiedad (impuesto sobre bienes inmuebles); finanzas públicas; justicia tributaria; investigación de operaciones; modelando con la programación no lineal.

An optimization model for rates of socially fairer property tax

This article presents a nonlinear mathematical optimization model that determines new rates for the Urban Property Tax (IPTU) on the residential apartments in the city of Salvador (BA). It considers the progressive increase in rates, the market values of properties, the taxpayers' average incomes, and the usual methodologies of the tax system. The results obtained in applying this model demonstrate that is possible to set tax rates in an objective and equitable manner in all kinds of urban property.

Key words: Land and Urban Property Tax (IPTU); public finance; tributary justice; operations research; nonlinear programming modeling.

\section{Introdução}

O estudo que ora apresentamos originou-se de um trabalho realizado na Secretaria da Fazenda da Prefeitura Municipal de Salvador (Sefaz-PMS) em 2009 que visava modernizar o Imposto sobre a propriedade Predial e Territorial Urbana (IPTU) do município, tendo como objetivo principal obter uma arrecadação superior à do ano anterior (2008) adotando-se uma política tributária mais justa e capaz de corrigir algumas distorções identificadas na metodologia de cálculo do tributo. Dessa forma, pretendia-se adequar a arrecadação do IPTU do município de Salvador ao seu porte socioeconômico, comparativamente a outras capitais do país. Idealizando uma nova modelagem para o IPTU direcionada aos objetivos pretendidos, foram então realizadas várias pesquisas, e efetivado o estudo que resultou no presente artigo. Foram considerados os seguintes fundamentos:

จ a legislação tributária, nos níveis federal, estadual e municipal, com ênfase nas leis, decretos e normas jurídicas incidentes sobre o IPTU;

จ o perfil estimado das rendas médias mensais dos contribuintes e suas respectivas capacidades contributivas, e a progressividade das alíquotas;

os principais fundamentos da metodologia de cálculo do IPTU praticada no município de Salvador, o banco de dados de 2008 relativo aos valores venais dos imóveis e a política tributária atual da Sefaz-PMS que estabelece as alíquotas mínima e máxima para todos os tipos (finalidades de uso) e padrões construtivos de imóveis;

v a utilização dos princípios, métodos e modelos da Pesquisa Operacional como instrumentos necessários à busca por uma solução ótima que satisfizesse todos os objetivos propostos para o IPTU, incluindo a especificação do modelo matemático mais adequado para se atingir esses objetivos;

v a construção de diversos modelos de otimização matemática, e a realização de simulações com estes modelos, tendo como objetivo precípuo a determinação de alíquotas ótimas 
coerentes com a capacidade contributiva dos munícipes e, deste modo, socialmente mais justas.

A partir desses fundamentos, é importante considerar que a justiça social, neste sentido, tornou-se um critério sempre presente a partir da Constituição Federal de 1988, que estruturou o IPTU observando essa diretriz. Boquimpani (2007), baseado no Estatuto da Cidade (Lei no 10.257 , de 10 de julho de 2001), sustenta a tese de que a justiça tributária é imperativa para superar as desigualdades sociais urbanas em um estado social de direito. Abdala (2008) procurou avaliar se há uma correlação significativa entre a receita orçamentária dos municípios, em termos per capita, e seus respectivos graus de desenvolvimento humano (IDH), mediante um modelo econométrico com dados de uma amostra envolvendo 2.264 cidades brasileiras no período 1991-2000. Os municípios foram agregados conforme a região geográfica e o tamanho da população residente objetivando-se a possibilidade de se testar a robustez dos resultados preliminares. Através da estabilidade dos resultados, independentemente dos agrupamentos, concluiu-se que a relação entre a receita tributária per capita municipal e o IDH mostrou-se muito fraca, embora estatisticamente significante, e quanto piores os indicadores sociais do município observado, maior era o aumento marginal esperado no IDH em função dos acréscimos em sua arrecadação per capita.

Geralmente, os critérios utilizados para a promoção da justiça social são o da progressividade das alíquotas e o da isenção. Os valores das alíquotas e os critérios de isenção são estabelecidos nos códigos tributários dos municípios, a exemplo do Código Tributário e de Rendas do Município do Salvador (Lei no 7.186, de 27 de dezembro de 2006). Para que o cidadão possa usufruir a isenção do IPTU é suficiente a comprovação de que preenche as exigências legais. Quanto à aplicação ou não de alíquotas progressivas, e em que intensidade, isto fica definido nas metodologias de cálculo adotadas pelos municípios. O IPTU torna-se progressivo quando suas alíquotas são definidas em função da capacidade contributiva dos munícipes, de modo coerente.

Assim, para a efetivação da justiça tributária quando da aplicação do imposto, torna-se importante buscar o desenvolvimento de um estudo criterioso visando estabelecer metodologias de cálculo mais eficientes para o IPTU, em que os critérios de progressividade estejam explícita e criteriosamente presentes. E para se harmonizar justiça social com aumento da arrecadação torna-se necessária a determinação de alíquotas progressivas adequadas em relação a esses dois objetivos.

O incremento da arrecadação depende a priori da utilização de uma ou mais das seguintes alternativas: aumento do valor das alíquotas, atualização da Planta Genérica de Valores Imobiliários (PGVI), tornando o valor venal dos imóveis o mais próximo possível do valor de mercado, e ampliação do cadastro de imóveis para tributação junto ao órgão fazendário (Carvalho Jr., 2006). Pelegrina (2009) cita em sua pesquisa que, entre os problemas mais comuns na gestão do IPTU, sobressaem-se as falhas na legislação tributária e os cadastros desatualizados, e que os cadastros existentes nas cidades brasileiras resumem-se a inventários oficiais dos limites físicos das propriedades e de suas benfeitorias, tendo como objetivo apenas a tributação imobiliária. Opina ainda que a solução ideal seria a implantação de um Cadastro Territorial Multifinalitário (CTM), dado que suas funções são de natureza econômica e social, 
podendo servir como um apoio para o combate à pobreza através do aperfeiçoamento dos processos de regularização fundiária e segurança jurídica, além do monitoramento ambiental.

\section{Referencial teórico}

Na nova modelagem do IPTU do município de Salvador, foram consultadas as seguintes referências, que contribuíram de modo efetivo e vital, com informações e dados relevantes para se atingir os fins propostos:

、 Os fundamentos relativos à criação, princípios, diretrizes e aplicação do IPTU, proveniente de diversos instrumentos jurídicos, tais como: a Constituição da República Federativa do Brasil de 1988, o Código Tributário Nacional — CTN (Lei no 5.172, de 25 de outubro de 1966), o Estatuto da Cidade (Lei no 10.257, de 10 de julho de 2001), o Código Tributário e de Rendas do Município de Salvador - CTRMS (Lei no 7.186, de 27 de dezembro de 2006), e os decretos municipais que dispõem sobre as correções do IPTU: ํㅜ 9.207, de 11 de novembro de 2001, ํㅜ 14.116, de 27 de dezembro de 2002, e oㅜ 19.223, de 29 de dezembro de 2008;

v Informações básicas sobre os aspectos legais, operacionais e administrativos do IPTU, como as questões da uniformidade, progressividade e regressividade do imposto, renda e capacidade contributiva, e os princípios que norteiam o IPTU, obtidos de: Ballarini (2010), Vasques (2009), Oliveira (2009), Camargo (2008), Barbosa (2007), Boquimpani (2007), Fraga (2007), Carvalho Jr. (2006), Fernandes (2005), Palermo (2005), Furlan (2004), De Cesare (2002) e Garson (2001).

v A utilização da metodologia da Pesquisa Operacional na modelagem proposta, e sua contribuição para a elaboração e simulação de um modelo matemático apropriado para o IPTU de Salvador e necessário ao desenvolvimento socioeconômico da cidade, pesquisados em: Colin (2007), Arenales e colaboradores (2006), Bazaraa e colaboradores (2006) e Hillier e Lieberman (2005).

\subsection{Progressividade, uniformidade e capacidade contributiva}

De Cesare (2002) ressalta a existência de dois tipos de progressividade: fiscal e extrafiscal. A progressividade extrafiscal consiste na aplicação de alíquotas crescentes no tempo, à medida que prazos estabelecidos pelo poder público para o adequado aproveitamento do solo urbano não são cumpridos. No Brasil, ela é muito aplicada no caso de terrenos sem edificações. Já a progressividade fiscal consiste no estabelecimento de alíquotas coerentes com a capacidade contributiva dos cidadãos.

Várias pesquisas são favoráveis à adoção dos princípios da progressividade e uniformidade do imposto, e da capacidade contributiva dos cidadãos, e os recomendam, não só pela fundamentação legal, como também pelo favorecimento à justiça social. 
Destas, são relevantes: a de Bucher (1996), que considera o Princípio da Progressividade como o instrumento adequado para acionar a Função Social do IPTU. Embora reconheça que a Constituição Federal de 1988 validou juridicamente a aplicação da progressividade no IPTU, garantindo sua eficácia, sua regulamentação que era esperada pela norma geral não aconteceu, e os municípios sem uma orientação jurídica padronizada passaram a aplicá-lo de acordo com sua conveniência, existindo atualmente inúmeros procedimentos diversificados.

Payeras (2008) realizou uma pesquisa sobre a carga tributária no Brasil e sua distribuição, desenvolvendo um modelo capaz de captar como as diferentes classes de renda são afetadas pelas mudanças nas alíquotas dos tributos. O modelo foi baseado na carga tributária por faixa de renda, considerando a estimação de uma matriz de elasticidade marshalliana e o padrão de consumo da população, com as simulações sendo realizadas com base nos microdados da Pesquisa de Orçamento Familiar (POF) do IBGE, no período de 2002-03. Foi realizado um estudo da atual incidência do sistema tributário brasileiro considerando as cargas tributárias direta, indireta e total por faixa de renda até a estimação de um modelo de sacrifício equitativo. A conclusão da pesquisa foi que o sistema tributário brasileiro é regressivo em relação à renda, graças em grande parte aos impostos indiretos.

Bonetti (1997) procura demonstrar a relação da progressividade nos impostos com os princípios da Igualdade e da Capacidade Contributiva, e, no caso particular do IPTU, também com a Função Social da Propriedade, em que também é possível a aplicação da progressividade como sanção (extrafiscal).

Carrazza (1992) demonstra que a progressividade do IPTU relaciona-se com a capacidade de pagamento dos contribuintes. E que, considerando-se a condição de igualdade, deverá ser aplicado o princípio da isonomia. A progressividade dos impostos é defendida como um instrumento de superação das injustiças e desigualdades sociais, como também uma forma de se acatar o princípio da capacidade contributiva.

Palermo (2005) analisou o Princípio da Capacidade Contributiva considerando os limites de sua aplicabilidade à luz da Constituição Federal de 1988, com ênfase na análise conceitual do princípio e enfocando-o como instrumento de política fiscal apto a possibilitar maiores equidade tributária e arrecadação do imposto (IPTU).

De Cesare (2002) sustenta que um dos requisitos fundamentais para uma tributação imobiliária eficiente é a manutenção da uniformidade de valor entre as unidades imobiliárias de mesma categoria e um quociente constante entre os valores avaliados e os de mercado para todos os imóveis, nas avaliações realizadas para fins tributários. Entretanto, frequentemente são identificadas iniquidades relacionadas a esses dois fatores na base de cálculo dos impostos.

Pelo fato de existir uma fundamentação jurídica amparada pela Constituição em torno do assunto, pode-se inferir que uma nova modelagem para o IPTU comporta a aplicação dos princípios da progressividade e da uniformidade do imposto, em função da capacidade contributiva dos cidadãos. O tema sempre provoca nos gestores do imposto uma motivação natural e vontade política para a ampliação da justiça social, dado que a falta de uma correlação perfeita entre a capacidade de pagamento dos contribuintes e o valor do imposto sobre 
a propriedade pode redundar em um processo confiscatório, que é vedado pelo princípio constitucional do "não confisco".

\subsection{Imposto sobre a Propriedade Predial e Territorial Urbana (IPTU) no Brasil}

Os procedimentos adotados pelos municípios brasileiros variam consideravelmente e, portanto, vigoram diversas metodologias de cálculo do imposto, algumas apresentando progressividade linear ou não linear, outras regressivas, existindo desse modo uma ampla liberdade de ação com relação ao desenvolvimento de novos modelos para o imposto.

A Constituição Federal (1988) em seus arts. 156 e 182 definiu as principais diretrizes do IPTU e recomenda a conciliação de sua arrecadação com os princípios da justiça tributária e social. De acordo com o capítulo III, Seção II, art. 32 do Código Tributário Nacional (CTN), o IPTU é um imposto municipal. Consequentemente, sua administração, políticas e diretrizes a ele relacionadas, bem como sua metodologia de cálculo, são estabelecidas na esfera dos municípios.

Em seu art. 33, o CTN estabelece que o cálculo do IPTU de um imóvel é determinado por meio do produto de uma alíquota pelo valor venal da propriedade, considerando a terra e suas benfeitorias (construções) de caráter permanente, sem incluir o valor de outros bens mantidos no imóvel, em caráter permanente ou temporário, para a finalidade de sua utilização e/ou exploração. Então, a base de cálculo do IPTU é o valor venal da unidade imobiliária e, como não existe ainda um procedimento padrão legal para o seu cálculo que possa atender de modo efetivo todos os municípios brasileiros, quaisquer que sejam suas peculiaridades socioeconômicas, ele continua sendo calculado conforme o CTN.

Um caso especial para o IPTU muito frequente no Brasil é o de terrenos não edificados que, em consequência da progressividade extrafiscal, são penalizados com uma tributação superior à dos imóveis construídos (Carvalho Jr., 2006). A progressividade extrafiscal prevista no art. 7ํ do Estatuto das Cidades, e no art. 182, § 4ํㅡㄹ da Constituição Federal de 1988, consiste na aplicação de alíquotas crescentes no tempo, à medida que prazos estabelecidos pelo poder público para o aproveitamento adequado do solo urbano não são cumpridos.

O valor venal de uma unidade imobiliária para fins de tributação é constituído pela soma do valor venal do terreno com o da edificação. O tipo e o padrão construtivo do imóvel, assim como sua área e localização, influenciam no valor da construção. Quando em um determinado município existe uma Planta Genérica de Valores Imobiliários (PGVI), cada região ou via pública possui um determinado valor por metro quadrado e consegue-se estabelecer o valor do terreno de cada logradouro por um período de tempo, já que o mercado imobiliário é dinâmico. Assim, o valor total de um terreno poderá ser calculado multiplicando-se sua área total pelo valor do metro quadrado. Por outro lado, as finalidades de uso (tipos) e os padrões construtivos são os fundamentos que servem como base para determinação do valor venal das edificações.

Sobre as alíquotas do IPTU, em Carvalho Jr. (2006) vimos que no Brasil existem vários critérios para o estabelecimento de seus importes: valor venal, padrão construtivo, localiza- 
ção e tamanho dos imóveis. Um sistema regressivo de tributação admite uma única alíquota que é aplicada a todos os imóveis independentemente de seu valor venal, ou qualquer outro critério adotado para sua valoração. Já em um sistema progressivo, torna-se necessário um conjunto de alíquotas (pelo menos duas) hierarquizadas por valor que deve manter uma relação de pertinência com os níveis adotados de valoração dos imóveis. Em algumas cidades funciona um sistema progressivo em que os importes das alíquotas são variados de acordo com um dos critérios citados, em outras, são adotados mais de um critério. Em Belém, Belo Horizonte, Curitiba, Fortaleza, Natal, Recife e São Paulo é adotado um sistema de IPTU progressivo, no qual as alíquotas são determinadas em função do valor venal dos imóveis. Goiânia e Florianópolis também admitem um regime de progressividade, porém os critérios adotados são localização e tamanho das unidades imobiliárias, respectivamente. Em Salvador, a progressividade das alíquotas é baseada no padrão construtivo das propriedades. Algumas cidades, como Nova Iguaçu e São Gonçalo, praticam um sistema progressivo de alíquotas relacionado a mais de um critério: valor venal e localização. Por outro lado, Brasília, Aracaju, Cuiabá, João Pessoa, Porto Alegre, Rio de Janeiro e Vitória permanecem com um sistema regressivo de alíquotas. Considerando o IPTU de algumas capitais brasileiras de porte similar a Salvador, temos que:

a) Em Porto Alegre, não existe progressividade. Vigora apenas uma alíquota para cada tipo de imóvel (residencial e não residencial). Porém, são atribuídas uma alíquota reduzida aos imóveis utilizados na produção agrícola, e alíquotas mais elevadas aos terrenos não edificados (progressividade extrafiscal), conforme a tabela 1.

Tabela 1

\section{Alíquotas do IPTU aplicadas no município de Porto Alegre}

\begin{tabular}{|lc|}
\hline Tipo de imóvel & Alíquota \\
\hline Residencial & $0,85 \%$ \\
Não residencial & $1,10 \%$ \\
Utilizado na produção agrícola & $0,03 \%$ \\
Terreno não edificado & $1,5 \%$ a $6,0 \%$ \\
Terreno com projeto arquitetônico $\left(^{*}\right)$ & $0,95 \%$ \\
Terreno com projeto arquitetônico $\left(^{* *}\right)$ & $1,20 \%$ \\
\hline
\end{tabular}

Fonte: Elaboração própria baseada nos dados da Prefeitura Municipal de Porto Alegre - Secretaria da Fazenda (2010).

* Projeto de imóvel residencial aprovado pela Prefeitura.

** Projeto de imóvel não residencial aprovado pela Prefeitura.

b) Em Recife, vigoram cinco alíquotas para cada tipo de imóvel incidentes sobre igual número de faixas de valores venais. Existe progressividade linear nos dois casos (tabela 2). 
Tabela 2

Alíquotas do IPTU aplicadas no município de Recife

\begin{tabular}{|c|c|c|c|}
\hline \multicolumn{2}{|c|}{ Faixas de valores venais (em $\mathrm{R} \$$ ) } & \multirow{2}{*}{$\begin{array}{c}\text { Alíquota } \\
\text { Residenciais }\end{array}$} & \multirow{2}{*}{$\begin{array}{c}\text { Alíquota } \\
\text { Não residenciais }\end{array}$} \\
\hline $\mathrm{De}$ & Até & & \\
\hline- & $17.631,21$ & $0,60 \%$ & $1,00 \%$ \\
\hline $17.631,21$ & $65.588,10$ & $0,80 \%$ & $1,25 \%$ \\
\hline $65.588,10$ & $153.038,90$ & $1,00 \%$ & $1,50 \%$ \\
\hline $153.038,90$ & $349.097,95$ & $1,20 \%$ & $1,75 \%$ \\
\hline \multirow[t]{2}{*}{$349.097,95$} & $>349.097,95$ & $1,40 \%$ & $2,00 \%$ \\
\hline & \multicolumn{2}{|c|}{ Imóveis não edificados (terrenos) = } & $3,00 \%$ \\
\hline
\end{tabular}

Fonte: Elaboração própria baseada nos dados da Prefeitura Municipal do Recife - Secretaria de Finanças (2010).

c) Em Fortaleza, existem três alíquotas para os imóveis residenciais e duas para os não residenciais. O sistema adota também redutores para cada faixa, conforme a tabela 3.

Tabela 3

Alíquotas do IPTU aplicadas no município de Fortaleza

\begin{tabular}{|c|c|c|c|c|}
\hline \multicolumn{2}{|c|}{ Faixas de valores venais (em $R \$$ ) } & \multirow{2}{*}{$\begin{array}{c}\text { Alíquota } \\
\text { Residenciais }\end{array}$} & \multirow{2}{*}{$\begin{array}{c}\text { Alíquota } \\
\text { Não residenciais }\end{array}$} & \multirow[t]{2}{*}{ Redutor (em R\$) } \\
\hline $\mathrm{De}$ & Até & & & \\
\hline- & $58.500,00$ & $0,60 \%$ & $1,00 \%$ & Não há \\
\hline $58.500,00$ & $210.600,00$ & $0,80 \%$ & $1,00 \%$ & 117,00 \\
\hline $210.600,00$ & $>210.600,00$ & $1,40 \%$ & $2,00 \%$ & $1.380,00$ \\
\hline \multicolumn{2}{|c|}{ Terrenos não edificados $(*)$} & & $1,00 \%$ & Não há \\
\hline \multicolumn{2}{|c|}{ Terrenos não edificados (**) } & & $2,00 \%$ & $2.106,00$ \\
\hline
\end{tabular}

Fonte: Elaboração própria baseada nos dados da Prefeitura Municipal de Fortaleza - Secretaria de Finanças - Sefin (2010).

* Logradouros em áreas desprovidas de infraestrutura Urbana.

** Logradouros em áreas que possuam infraestrutura Urbana.

d) Em Belo Horizonte são utilizadas três alíquotas linearmente progressivas para os imóveis residenciais e uma para os não residenciais (regressividade), conforme tabela 4. 
Tabela 4

Alíquotas do IPTU aplicadas no município de Belo Horizonte

\begin{tabular}{|c|c|c|c|}
\hline \multicolumn{2}{|c|}{ Faixas de valores venais (em $\mathrm{R} \$$ ) } & \multirow{2}{*}{$\begin{array}{c}\text { Alíquota } \\
\text { Residenciais }\end{array}$} & \multirow{2}{*}{$\begin{array}{c}\text { Alíquota } \\
\text { Não residenciais }\end{array}$} \\
\hline $\mathrm{De}$ & Até & & \\
\hline- & $350.000,00$ & $0,80 \%$ & $1,60 \%$ \\
\hline $350.000,00$ & $500.000,00$ & $0,90 \%$ & $1,60 \%$ \\
\hline $500.000,00$ & $>500.000,00$ & $1,00 \%$ & $1,60 \%$ \\
\hline \multicolumn{3}{|c|}{ Terrenos não edificados (*) } & $1,00 \%$ \\
\hline \multicolumn{3}{|c|}{ Terrenos não edificados (**) } & $3,00 \%$ \\
\hline
\end{tabular}

Fonte: Elaboração própria baseada nos dados da Prefeitura Municipal de Belo Horizonte - Secretaria de Finanças (2010).

* Logradouros com menos de três melhoramentos.

** Logradouros com três ou mais melhoramentos.

e) Em Curitiba encontra-se a metodologia mais sofisticada para o cálculo do IPTU. O sistema admite nove alíquotas para os imóveis residenciais e cinco para os não residenciais (progressividade não linear em ambos os casos). Sobre os terrenos não edificados, são aplicadas cinco alíquotas linearmente progressivas. O sistema admite ainda dois tipos de progressividade: a do imposto recomendada pela Constituição Federal e a progressividade graduada oriunda do cálculo do valor do imóvel (efeito "cascata"), conforme o item "Observação" na tabela 5.

Tabela 5

Alíquotas do IPTU aplicadas no município de Curitiba

\begin{tabular}{|c|c|c|c|c|c|}
\hline \multicolumn{2}{|c|}{ Faixas de valores venais (em $\mathrm{R} \$$ ) } & \multirow{2}{*}{$\begin{array}{l}\text { Alíquota imóveis } \\
\text { residenciais }\end{array}$} & \multicolumn{2}{|c|}{ Faixas de valores venais (em $\mathrm{R} \$$ ) } & \multirow{2}{*}{$\begin{array}{c}\text { Alíquota de } \\
\text { terrenos }\end{array}$} \\
\hline $\mathrm{De}$ & Até & & $\mathrm{De}$ & Até & \\
\hline- & $29.271,00$ & $0,20 \%$ & & $14.634,00$ & $1,00 \%$ \\
\hline $29.271,01$ & $36.647,00$ & $0,25 \%$ & $14.634,01$ & $29.271,00$ & $1,50 \%$ \\
\hline $36.647,01$ & $51.283,00$ & $0,35 \%$ & $29.271,01$ & $43.906,00$ & $2,00 \%$ \\
\hline $51.283,01$ & $65.919,00$ & $0,55 \%$ & $43.906,01$ & $73.177,00$ & $2,50 \%$ \\
\hline $65.919,01$ & $95.190,00$ & $0,75 \%$ & $73.177,01$ & $>73.177,00$ & $3,00 \%$ \\
\hline $95.190,01$ & $139.097,00$ & $0,85 \%$ & & & \\
\hline $139.097,01$ & 139.097,00 & $0,95 \%$ & \multirow{2}{*}{\multicolumn{3}{|c|}{$\begin{array}{l}\text { Observação - A tabela de alíquotas é progressiva graduada } \\
\text { em razão do valor do imóvel. De modo que: }\end{array}$}} \\
\hline $183.004,01$ & $223.910,00$ & $1,00 \%$ & & & \\
\hline $226.910,01$ & $>226.910,00$ & $1,10 \%$ & \multicolumn{3}{|c|}{$\begin{array}{l}\text { a) Imóveis residenciais de até } R \$ 29.271,00 \text { pagam alíquota } \\
\text { de } 0,20 \% \text {. }\end{array}$} \\
\hline \multicolumn{2}{|c|}{ Faixas de valores venais (em $\mathrm{R} \$$ ) } & Alíquota imóveis & \multirow{2}{*}{\multicolumn{3}{|c|}{$\begin{array}{l}\text { b) Os imóveis acima desse valor também começam com a } \\
\text { alíquota de 0,20\% sobre os primeiros R\$ 29.271,00. }\end{array}$}} \\
\hline $\mathrm{De}$ & Até & não residenciais & & & \\
\hline- & $36.649,00$ & $0,35 \%$ & \multirow{5}{*}{\multicolumn{3}{|c|}{$\begin{array}{l}\text { c) O que exceder esse valor até } R \$ 36.647,00 \text { ( } 2^{\circ} \text { teto) ou } \\
\text { seja: } R \$ 7.376,00 \text { será tributado em } 0,25 \% \text {. } \\
\text { d) O que exceder os primeiros } R \$ 36.647,00 \text { até o } 3^{\circ} \text { teto } \\
\text { de } R \$ 51.283,00 \text { será tributado em } 0,35 \% \text {. E assim } \\
\text { sucessivamente. }\end{array}$}} \\
\hline $36.649,01$ & $51.283,00$ & $0,55 \%$ & & & \\
\hline $51.283,01$ & $65.919,00$ & $0,85 \%$ & & & \\
\hline $65.919,01$ & $80.555,00$ & $1,60 \%$ & & & \\
\hline $80.555,01$ & $>80.555,00$ & $1,80 \%$ & & & \\
\hline
\end{tabular}

Fonte: Elaboração própria baseada nos dados da Prefeitura Municipal de Curitiba - Secretaria de Finanças (2010). 


\subsection{A distribuição da carga tributária}

A equidade na aplicação do imposto é entendida como a relação coerente entre o importe a ser pago e a capacidade de pagamento do contribuinte, a qual está diretamente relacionada com sua renda. Na gestão tributária do município de Salvador já existe um consenso a respeito da compatibilidade entre esses dois fatores, e são utilizadas alíquotas progressivas de acordo com o padrão construtivo da propriedade. Porém, a questão crucial é se o grau de progressividade adotado é o mais apropriado para o município.

Com base em informações originárias da Associação Brasileira de Empresas de Pesquisa (Abep), obtida dos relatórios Critério de Classificação Econômica Brasil (CCEB), na Web, temos, nas tabelas 6 e 7, dados sobre a composição social de Salvador e do Brasil em 2008, e sobre a evolução da renda média familiar no Brasil no período 2005-08.

Na tabela 6, percebe-se que as três classes menos favorecidas de Salvador (C2, D e E) concentram um percentual da população $(63,3 \%)$ bem superior ao do Brasil $(43,4 \%)$, enquanto o contrário acontece com as outras classes. Isso significando que, do ponto de vista social, Salvador não está bem posicionada com relação ao contexto social do país.

Tabela 6

Composição social em Salvador e no Brasil (2008)

\begin{tabular}{|lrrrrr|}
\hline \multirow{2}{*}{$\begin{array}{l}\text { Classes sociais } \\
\text { (critério Abep) }\end{array}$} & \multicolumn{2}{c}{ Composição social } & & \multicolumn{2}{c|}{ Composição social acumulada } \\
\cline { 2 - 3 } \cline { 6 - 6 } \cline { 5 - 6 } A1 & Salvador & Brasil & & Salvador & Brasil \\
\hline A2 & $0,50 \%$ & $0,60 \%$ & & $0,50 \%$ & $0,60 \%$ \\
B1 & $2,50 \%$ & $4,40 \%$ & & $3,00 \%$ & $5,00 \%$ \\
B2 & $6,80 \%$ & $9,10 \%$ & & $9,80 \%$ & $14,10 \%$ \\
C1 & $9,40 \%$ & $18,00 \%$ & & $19,20 \%$ & $32,10 \%$ \\
C2 & $17,50 \%$ & $24,50 \%$ & & $36,70 \%$ & $56,60 \%$ \\
D & $31,50 \%$ & $23,90 \%$ & & $68,20 \%$ & $80,50 \%$ \\
E & $28,40 \%$ & $17,90 \%$ & & $96,60 \%$ & $98,40 \%$ \\
Total & $3,40 \%$ & $1,60 \%$ & & $100,00 \%$ & $100,00 \%$ \\
\hline
\end{tabular}

Fonte: Associação Brasileira de Empresas de Pesquisa (2009).

Mediante a análise dos dados da tabela 7 observa-se que, no Brasil e, consequentemente, no município de Salvador, as rendas médias familiares são distribuídas exponencialmente de acordo com as classes sociais, podendo-se inferir que a capacidade contributiva dos munícipes, por estar diretamente relacionada às suas rendas, segue a mesma tendência. 
Tabela 7

Renda média familiar no Brasil, por classe social, no período (2005 a 2008)

\begin{tabular}{|ccccc|}
\hline Classes sociais & \multicolumn{4}{c|}{ Renda média familiar - critério Abep (em R\$) } \\
\cline { 2 - 5 } (critério Abep) & 2005 & 2006 & 2007 & \multicolumn{1}{c|}{2008} \\
\hline A1 & $9.733,47$ & $10.697,00$ & $14.250,00$ & $14.366,00$ \\
A2 & $6.563,73$ & $6.556,00$ & $7.557,00$ & $8.099,00$ \\
B1 & $3.479,36$ & $3.913,00$ & $3.994,00$ & $4.558,00$ \\
B2 & $2.012,67$ & $2.107,00$ & $2.256,00$ & $2.327,00$ \\
C1 & $1.194,53$ & $1.288,00$ & $1.318,00$ & $1.391,00$ \\
C2 & 726,26 & 849,00 & 861,00 & 933,00 \\
D & 484,97 & 549,00 & 573,00 & 618,00 \\
E & 276,70 & 318,00 & 329,00 & 403,00 \\
\hline
\end{tabular}

Fonte: Associação Brasileira de Empresas de Pesquisa (2009).

De acordo com dados do IBGE aferidos no biênio 2002-03, a participação do pagamento do IPTU na renda familiar dos contribuintes das capitais brasileiras, embora não seja a ideal, é mais amena naquelas cidades que adotam um sistema de alíquotas progressivas (tabelas 8 e 9).

Tabela 8

Participação do pagamento do IPTU na renda familiar mensal dos contribuintes em capitais de estados brasileiros que adotam critérios de progressividade nas alíquotas (Dados do Biênio 2002-03)

\begin{tabular}{|lcccccc|}
\hline & \multicolumn{7}{c}{ Salários mínimos } \\
\cline { 2 - 7 } \multicolumn{1}{c}{ Capitais } & $\mathbf{0}$ a 2 & 2 a 5 & 5 a 15 & 15 a 30 & 30 a 60 & 60 ou mais \\
\hline Belém & $0,14 \%$ & $0,12 \%$ & $0,14 \%$ & $0,31 \%$ & $0,04 \%$ & $0,07 \%$ \\
Belo Horizonte & $1,05 \%$ & $0,82 \%$ & $0,81 \%$ & $0,61 \%$ & $0,64 \%$ & $0,68 \%$ \\
Curitiba & $0,23 \%$ & $1,24 \%$ & $0,74 \%$ & $0,54 \%$ & $0,76 \%$ & $0,48 \%$ \\
Fortaleza & $0,37 \%$ & $0,36 \%$ & $0,43 \%$ & $0,74 \%$ & $0,63 \%$ & $0,12 \%$ \\
Goiânia & $1,06 \%$ & $0,65 \%$ & $0,39 \%$ & $0,68 \%$ & $1,12 \%$ & $0,88 \%$ \\
Salvador & $0,43 \%$ & $0,52 \%$ & $0,55 \%$ & $0,26 \%$ & $1,71 \%$ & $1,51 \%$ \\
São Paulo & $3,18 \%$ & $1,87 \%$ & $1,08 \%$ & $0,73 \%$ & $0,56 \%$ & $0,53 \%$ \\
\hline
\end{tabular}

Fonte: Elaboração própria baseada em Carvalho Jr. (2006).

No entanto, observa-se na tabela 8 que as capitais São Paulo, Belo Horizonte e Goiânia, apesar de utilizarem alíquotas progressivas, denotam ausência de justiça tributária por aplicarem um grau de progressividade incoerente com a capacidade de pagamento dos contribuintes. A participação do IPTU sobre a renda familiar da classe com menor renda (zero a dois 
salários mínimos) é mais do que o dobro de outras cidades, e as classes de renda mais elevada pagam relativamente menos imposto do que as classes menos favorecidas.

Além disso, vimos anteriormente que o IPTU de Recife (tabela 2) e de Curitiba (tabela 5) apresentam alíquotas para os imóveis residenciais dotadas, respectivamente, de progressividade linear e não linear, mas também sem ser exponencial, como o caso das rendas médias familiares visto na tabela 7. Essa falta de compatibilidade contribui para a presença de distorções no que se refere à participação do pagamento do IPTU nas rendas familiares referentes às diversas classes sociais. Vale ressaltar que as alíquotas do IPTU praticadas nas capitais que adotam a progressividade, à exceção de Curitiba, apresentam um número pequeno de alíquotas (menor ou igual a cinco), o que não é recomendável, pois as classes sociais brasileiras são geralmente representadas mediante uma estratificação maior, e deveria haver pelo menos uma alíquota para cada classe. Pelos critérios da Abep e do IBGE, existem respectivamente oito e seis classes sociais, bem delimitadas pelas respectivas faixas de rendas familiares.

No caso das capitais que não aplicam critérios de progressividade no cálculo do IPTU, o peso do imposto sobre a renda familiar é ainda maior, como se vê na tabela 9. As classes de renda familiar mais baixas (zero a dois salários mínimos) comprometem mais do que o dobro do percentual da renda familiar que é comprometida pelas famílias de mesma classe nas cidades que adotam critérios de progressividade.

Tabela 9

Participação do pagamento do IPTU na renda familiar mensal dos contribuintes em capitais de estados brasileiros que não adotam critérios de progressividade nas alíquotas (Dados do Biênio 2002-03)

\begin{tabular}{|lcccccc|}
\hline & \multicolumn{7}{c|}{ Salários mínimos } \\
\cline { 2 - 7 } \multicolumn{1}{c}{ Capitais } & $\mathbf{0}$ a 2 & 2 a 5 & 5 a 15 & 15 a 30 & 30 a 60 & 60 ou mais \\
\hline Aracaju & $5,79 \%$ & $0,56 \%$ & $0,68 \%$ & $0,27 \%$ & $0,17 \%$ & $0,74 \%$ \\
Braślia & $(*)$ & $3,86 \%$ & $0,94 \%$ & $0,92 \%$ & $0,27 \%$ & $0,47 \%$ \\
Cuiabá & $4,60 \%$ & $3,15 \%$ & $2,27 \%$ & $1,92 \%$ & $1,88 \%$ & $0,59 \%$ \\
João Pessoa & $1,39 \%$ & $0,86 \%$ & $0,65 \%$ & $0,40 \%$ & $0,26 \%$ & $1,86 \%$ \\
Porto Alegre & $1,47 \%$ & $1,50 \%$ & $0,92 \%$ & $0,72 \%$ & $2,43 \%$ & $0,85 \%$ \\
Rio de Janeiro & $1,60 \%$ & $1,92 \%$ & $1,28 \%$ & $3,43 \%$ & $0,66 \%$ & $0,47 \%$ \\
Vitória & $0,36 \%$ & $1,81 \%$ & $0,38 \%$ & $0,27 \%$ & $0,15 \%$ & $0,19 \%$ \\
\hline
\end{tabular}

Fonte: Elaboração própria baseada em Carvalho Jr. (2006).

* Dado não informado.

Então, o estabelecimento de um conjunto de alíquotas progressivas para o IPTU configura um problema de decisão importante no âmbito do planejamento tributário municipal, pois pode ainda evitar ou minimizar dois tipos de consequência danosa, uma referente à mo- 
bilidade forçada do segmento social de indivíduos de idade avançada para bairros e moradias mais humildes, e a outra, provocadora de evasão fiscal.

De acordo com Shan (2010), uma das consequências perversas do ponto de vista social é que proprietários idosos de bons imóveis vivendo da Previdência Social poderão ser induzidos a abdicar de suas moradias e migrar para outros imóveis e bairros de padrão inferior por não disporem mais de recursos para pagar o imposto sobre a propriedade. No estudo estatístico apresentado, as estimativas de ponto central sugerem que nos EUA um incremento de US\$ 100,00 no imposto anual de propriedade provoca um aumento percentual de 0,73\% em média nas taxas de mobilidade referentes a um período base de dois anos. Os resultados apresentados mostraram-se estatisticamente robustos para uma variedade considerável de testes de robustez. Esse autor conclui que os impostos sobre a propriedade são importantes em decisões de mudança dos proprietários idosos. Pode-se deduzir que no Brasil existe uma similaridade nesse sentido, dado que a aposentadoria oficial do INSS geralmente está aquém do rendimento de um trabalhador na ativa. Então, o idoso aposentado passa a ter uma renda restringida, provocando uma queda na qualidade de vida.

Vale salientar que a falta de compatibilidade entre o valor do imposto e a capacidade de pagamento dos contribuintes provoca ainda uma propensão à sonegação e evasão fiscal. Dhami e Al-Nowaihi (2010) fizeram uma pesquisa sobre a evasão fiscal nos EUA e conseguiram resultados díspares ao utilizarem duas metodologias científicas: a Teoria da Utilidade Esperada (EUT) e a Teoria do Prospecto (PT) no que se refere à escolha pelo governo de uma alíquota ótima para o imposto e à decisão de sonegar por um contribuinte em face da probabilidade de descoberta por uma auditoria e de penalidade pela sonegação. As conclusões mais importantes sobre a aplicação desses métodos foram que: as predições da Teoria da Utilidade Esperada aplicada à sonegação de imposto estão quantitativa e qualitativamente em discrepância com a evidência dos fatos, ao contrário da Teoria do Prospecto, que faz as predições corretas. E que os dados são mais bem descritos por contribuintes usando a Teoria do Prospecto e pelo governo usando a Teoria da Utilidade Esperada. Os resultados foram considerados robustos para diversas especificações alternativas possíveis, e mostraram que têm um peso significativo no debate entre liberalismo e paternalismo, em uma economia de caráter comportamentalista.

\subsection{O IPTU no município de Salvador, Brasil}

De acordo com o Censo do IBGE de 2010, o município de Salvador, isolado da RMS, possui 706,799 km² de área, conta com 2.676.606 habitantes e apresenta um IDH de 0,805, constituindo-se na maior cidade da região Nordeste em termos populacionais. De acordo com informações obtidas de relatórios e planilhas produzidos pela Coordenadoria de Tributos Imobiliários (CTI) da Sefaz-PMS, o sistema do IPTU de Salvador apresentou o seguinte perfil referente aos imóveis cadastrados em 2008: o segmento das propriedades residenciais (apartamentos e casas) mostrou-se majoritário no que se refere à quantidade de imóveis, apresentando $87,03 \%$ do total, embora essa parcela represente apenas 59,88\% em termos de valores 
venais. As propriedades comerciais e de serviços estão em segundo lugar, com 12,07\% do total de imóveis e constituindo $23,30 \%$ dos valores venais. As unidades imobiliárias industriais, e especiais e institucionais, são minoria, com, respectivamente, 0,17\% e 0,72\% da totalidade dos imóveis, embora representem 1,78\% e 15,05\% do total dos valores venais que compõem a base de cálculo. No contexto urbano de Salvador, 51,52\% dos imóveis residenciais são de padrão médio, simples e precário. Pode-se então deduzir que, na esfera social, são encontrados mais padrões de vida situados entre a pobreza e a classe média do que altos, assim como na maioria esmagadora das cidades nordestinas.

O atual processo de cálculo do IPTU de Salvador ampara-se na Lei ํㅜ 7.186, de 27 de dezembro de 2006, a qual instituiu o Código Tributário e de Rendas do Município do Salvador (CTRMS), e no Decreto no 9.207, de 11 de novembro de 1991, o qual dispõe sobre os elementos para a fixação da base de cálculo de terrenos e de edificações, para fatores de valorização e desvalorização, e avaliação especial de unidades imobiliárias. Posteriormente, o Decreto $\mathrm{n}^{\circ}$ 9.207 foi alterado pelos de ํㅜ 14.116 , de 27 de dezembro de 2002, e ํㅜ 19.223 , de 29 de dezembro de 2008, os quais fixaram os Valores Unitários Padrão (VUPs) de terrenos e atualizaram os valores para efeito de avaliação de unidade imobiliária e lançamento do IPTU. O valor venal das unidades imobiliárias é atualizado anualmente por meio da variação do Índice de Preços ao Consumidor Amplo Especial (IPCA-E) apurado pelo Instituto Brasileiro de Geografia e Estatística (IBGE). Na tabela 10 estão os valores dos VUPs de edificações e as alíquotas dos imóveis de Salvador por tipo e padrão construtivo para 2009.

De acordo com a Prefeitura Municipal de Salvador (2010), o cálculo do IPTU de cada imóvel do município é realizado mediante a aplicação de alíquotas aos seus valores venais principal e excedente, conforme o tipo e padrão construtivo em que está enquadrado:

Valor do Imposto $=[($ Alíquota. Valor Venal Principal $)+($ Alíquota de Terreno.

Valor Venal Excedente)]. Fator de Correção do Valor Venal

Em que:

Valor Venal Principal $=$ Valor Venal do Terreno + Valor Venal da Construção

Valor Venal do Terreno = Área de Uso Privativo. VUPt. Fator de Correção

Valor Venal da Construção = Área Construída. VUPc. Fator de Correção

Valor Venal Excedente = Área Excedente. VUPt. Fator de Correção

Área Excedente $=$ Área do Terreno - (5. Área da Construção)

VUPt $=$ Valor do $\mathrm{m}^{2}$ do Terreno

VUPc $=$ Valor do $\mathrm{m}^{2}$ da Construção

Fator de Correção = É um valor que se aplica ao Valor Venal da unidade imobiliária objetivando uma aproximação do valor de mercado.

Obs.: Quando a área do terreno ultrapassar cinco vezes a área construída, aplica-se a alíquota de terreno (mais onerosa) sobre o valor da área excedente. 


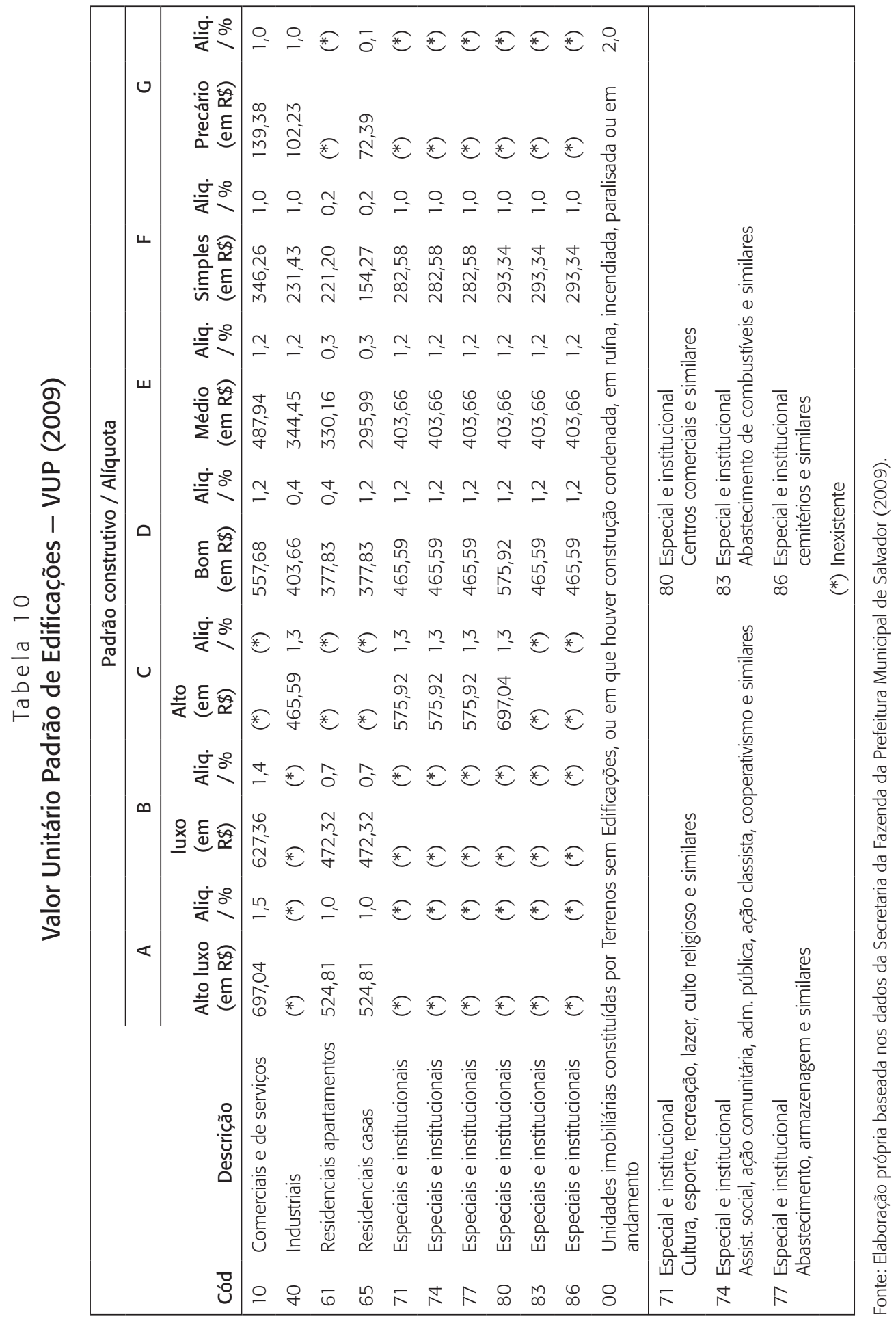


Para o cálculo da arrecadação global do IPTU de Salvador, são considerados cinco tipos de imóvel e sete padrões construtivos. Os tipos são: 1) Residenciais - Apartamentos, 2) Residenciais - Casas, 3) Comerciais e de Serviços, 4) Industriais, 5) Especiais e Institucionais. Os padrões construtivos são: 1) Alto Luxo, 2) Luxo, 3) Alto, 4) Bom, 5) Médio, 6) Simples, 7) Precário. Os imóveis de qualquer tipo geralmente não se enquadram em todos os padrões construtivos. Em 2009, existia ainda uma alíquota especial, e mais onerosa, para unidades imobiliárias constituídas por terrenos sem edificações, ou em que houver construção condenada, em ruína, incendiada, paralisada, ou ainda em andamento (tabela 10). A expressão matemática da Arrecadação Global do IPTU do município de Salvador é mostrada no apêndice $A$.

O estudo mostrado neste artigo, no entanto, foi realizado considerando apenas o tipo de imóvel (residencial - apartamentos) e a faixa de valor venal na qual ele está situado, em substituição ao padrão construtivo, uma vez que existe a alternativa de a Sefaz-PMS modificar a base de cálculo do IPTU com o objetivo de evitar distorções relacionadas à uniformidade do imposto.

\section{Procedimentos metodológicos}

Uma nova modelagem para o IPTU direcionada para eficiência tributária com justiça social visa a priori o estabelecimento de um conjunto de alíquotas progressivas que resulte em uma arrecadação ótima, observando-se o princípio da uniformidade tributária. O estudo visando um novo modelo para o IPTU foi pautado nas seguintes diretrizes:

จ Reavaliar inicialmente as alíquotas a serem adotadas para os imóveis residenciais (apartamentos).

- Testar a mudança do atual sistema de atribuição de alíquotas, utilizando-se de um determinado número de faixas de valores venais (intervalos) da base de cálculo, em substituição aos critérios relacionados ao padrão construtivo dos imóveis.

Experimentalmente, no caso do município de Salvador, foram consideradas diversas faixas de valor venal dos imóveis residenciais (apartamentos), pretendendo-se atingir dois objetivos imediatos: aumento da arrecadação do imposto com relação ao ano anterior (2008) e ampliação da justiça tributária, essa última tendo como consequência evitar a mobilidade e a evasão fiscal. Foram ainda considerados os dados vigentes da PGVI, uma vez que um processo de reavaliação não pode ser concretizado a curto ou médio prazo.

Para se resolver um problema de decisão, o qual envolve múltiplos aspectos, uma das opções recomendáveis consiste na utilização dos princípios, métodos e modelos da Pesquisa Operacional, que é uma área científica eminentemente voltada para o apoio aos processos decisórios e se constitui em uma opção efetiva para a resolução de problemas complexos (Arenales et al., 2006; Colin, 2007; Hillier e Liebermann, 2005). A otimização matemática, 
por ser uma técnica de Pesquisa Operacional muito eficiente quando se busca maximizar ou minimizar desempenhos em um sistema, tornou-se então uma alternativa viável para a modelagem do IPTU na busca por alíquotas ótimas. Portanto, foram desenvolvidos alguns modelos de otimização matemática buscando respostas satisfatórias inicialmente para o problema da definição de alíquotas do IPTU relativas aos imóveis residenciais (apartamentos) do município de Salvador. Esses modelos foram estruturados em conformidade com os seguintes fundamentos:

- Aplicação do princípio da progressividade de forma coerente com a renda média familiar brasileira, considerando as oito classes sociais definidas pelo critério da Abep, evitando-se manter a carga tributária na mesma proporção para contribuintes com diferentes capacidades contributivas, adotando-se, portanto, a progressividade exponencial.

- Cogitar a hipótese de que é possível conseguir o incremento da arrecadação do IPTU praticando-se justiça tributária, por meio da utilização de um modelo de otimização não linear paramétrica, considerando-o, portanto, o método mais adequado para se atingir os objetivos esperados.

- Substituir a atual sistemática, em que as alíquotas são determinadas de acordo com o padrão construtivo de cada tipo de imóvel, pela alternativa relacionada a faixas de valores venais (intervalos) nas quais os imóveis estão inseridos.

Portanto, foi construído preliminarmente um modelo piloto com o objetivo de testar a eficiência da otimização matemática na obtenção de alíquotas ótimas progressivas que pudessem conduzir a maiores arrecadações. A formulação clássica de um modelo de otimização matemática é constituída de uma função objetivo, a qual representa uma medida de desempenho que deve ser maximizada ou minimizada, sujeita a um conjunto de restrições representadas por equações e/ou inequações. A função objetivo e as restrições do modelo são determinadas em função de um conjunto de variáveis, denominadas variáveis de decisão (Hillier e Lieberman, 2005). Quando a função objetivo e/ou pelo menos uma das restrições não são funções lineares das variáveis de decisão, então temos um modelo de programação não linear (Bazaraa et al., 2006).

\subsection{0 modelo de otimização matemática para n alíquotas do IPTU}

O modelo de otimização matemática estruturado para $n$ alíquotas do IPTU foi desenvolvido observando-se as seguintes especificações:

a) A Função Objetivo foi estabelecida visando-se a maximização da diferença entre as alíquotas limites (máxima e mínima) determinadas para os imóveis residenciais, conforme a política tributária da Sefaz-PMS (item 1 do apêndice B), visando com este distanciamento conseguir uma maior justiça tributária, sendo considerados os valores de 0,20\% e 1,35\% 
para as alíquotas limites (itens 2 e 3 do apêndice B). Pretendeu-se com essa estrutura se obter um conjunto de alíquotas intermediárias distribuídas de forma exponencialmente progressiva, em conformidade com as rendas médias familiares do Brasil, mostradas na tabela 7, as quais melhorassem a arrecadação do IPTU com relação a um valor mínimo esperado, de forma socialmente justa.

b) As variáveis de decisão do modelo representaram as alíquotas ótimas do IPTU a serem obtidas para os imóveis residenciais (apartamentos) de Salvador. A princípio, foi considerado que o seu número poderia variar de oito a 12 alíquotas. Então, tornou-se necessário estabelecer um mesmo número de faixas de valores venais em ordem crescente, de modo que a cada uma fosse atribuída uma alíquota específica. Foi ainda estabelecido pela Sefaz-PMS que a alíquota mais onerosa teria de ser superior a $1,2 \%$.

c) Foi estabelecido um parâmetro de forma $\Theta$, com duas finalidades: moldar a distribuição das alíquotas na forma exponencial para induzir a alíquotas progressivas e possibilitar a flexibilização dos resultados encontrados na busca por uma solução econômica mais satisfatória (uma maior arrecadação), por meio de análise de sensibilidade. O parâmetro $\Theta$ só podendo admitir valor maior do que zero e menor ou igual a um (itens 4, 5, 6 e 7 do apêndice B).

d) As restrições do modelo (itens 2 a 11 do apêndice B), explicitadas por nove inequações e uma equação, foram contidas em seis agrupamentos com as seguintes finalidades:

1. Definição dos limites das alíquotas mínima e máxima;

2. Cálculo dos valores das alíquotas;

3. Hierarquização das alíquotas;

4. Determinação de incrementos proporcionais entre as alíquotas;

5. Cálculo do IPTU para os imóveis residenciais;

6. Limitação do incremento da arrecadação em face de um valor mínimo esperado.

O modelo piloto foi confeccionado visando ainda apresentar flexibilidade com relação aos resultados desejados em qualquer conjuntura, pois permite, mediante alteração em alguns dados, nas restrições ou no parâmetro de forma $\Theta$, a possibilidade de se conseguir resultados ótimos para qualquer situação específica. Vale ressaltar que, sem o citado parâmetro no modelo, o resultado obtido foi sofrível, apresentando um incremento de apenas $\mathrm{R} \$ 139.514,36$ na arrecadação, e ainda sem a possibilidade de utilizar o $\Theta$ para melhorar a solução. Então, no modelo piloto são permitidas as seguintes alterações:

- Embora a política tributária da Sefaz-PMS tenha estabelecido a priori os valores de 0,2\% e $1,35 \%$ para as alíquotas limites, os importes podem ser modificados, como também um dos limites pode ser excluído, e novos resultados ótimos serem obtidos.

v Objetivando-se arrecadações melhores ou alíquotas menores para as classes menos favorecidas, podem-se estabelecer valores diferenciados para o parâmetro de forma $\Theta$, obtendo-se novas soluções ótimas. 
- Pode-se ainda modificar a restrição em que a arrecadação do IPTU terá de ser apenas maior que o valor mínimo esperado, e determinar um percentual de incremento preestabelecido.

\section{Análise conclusiva dos resultados e trabalhos futuros}

O experimento do modelo piloto constituiu-se de duas aplicações na base de dados do IPTU relativa aos imóveis residenciais (apartamentos), considerando inicialmente nove alíquotas para igual número de faixas de valores venais, conforme a nova orientação para a base de cálculo do imposto. A primeira aplicação, com o objetivo de se obter alíquotas ótimas progressivas, mantendo-se uma arrecadação mínima de R \$ 50.616.514,58 esperada pela Sefaz-PMS, e a segunda, relaxando essa última restrição.

Por meio dos resultados obtidos da primeira aplicação, pôde-se constatar a possibilidade da ampliação da progressividade do IPTU mantendo-se a mesma arrecadação e beneficiando as classes menos favorecidas com alíquotas menores, o que é vantajoso em termos sociais, sem prejuízo financeiro para o órgão fazendário. Na segunda aplicação, ainda considerando nove alíquotas, os resultados mostraram que a arrecadação pode ser otimizada com progressividade do imposto, apresentando um incremento de $\mathrm{R} \$ 513.391,80$ sobre a arrecadação esperada, o que se configurou como uma solução vantajosa tanto para as classes menos favorecidas como para o órgão arrecadador.

Dados os bons resultados da aplicação do modelo piloto com nove alíquotas, na segunda fase, o modelo foi aplicado com a expansão das suas variáveis de decisão para 10, 11 e 12 alíquotas. Pretendeu-se nessa etapa verificar qual a melhor opção a ser adotada para o IPTU dos imóveis residenciais em termos de quantidade e valores das alíquotas. Os resultados ótimos para 10 e 11 alíquotas mostraram-se também satisfatórios em termos de arrecadação e valores das alíquotas, pois apresentaram progressividade exponencial, passível de evitar impacto social negativo. Entretanto, o modelo de 12 alíquotas, embora tenha apresentado uma solução ótima inferior à dos outros modelos com relação ao incremento da arrecadação (R \$ 355.911,31), foi considerado pela Sefaz-PMS socialmente mais justo.

Realizando-se um ajuste estatístico mediante regressão das alíquotas obtidas da solução inicial, obtém-se um coeficiente de determinação $\mathrm{R}^{2}$ de 98,08\% suficiente para caracterizar uma progressividade exponencial. No gráfico 1 podem-se visualizar as distribuições das alíquotas obtidas da solução inicial do modelo e do ajuste exponencial. No entanto, deve-se considerar que a arrecadação obtida com as alíquotas da regressão exponencial seria inviável, não só por transgredir uma diretriz da política tributária da Sefaz-PMS, pois produziria valores mais elevados para as duas primeiras alíquotas e uma alíquota máxima de 1,48626\%, acima do limite estabelecido, como também obteria uma arrecadação bem abaixo do valor esperado, conforme a tabela 11 . 
Tabela 11

Solução inicial do modelo de 12 alíquotas e o ajuste estatístico

\begin{tabular}{|c|c|c|c|c|c|c|}
\hline \multirow{3}{*}{$\begin{array}{c}\begin{array}{c}\text { Alíquotas } \\
\text { do IPTU }\end{array} \\
\mathrm{N}^{\mathrm{o}}\end{array}$} & \multicolumn{4}{|c|}{ Base de cálculo } & \multirow{3}{*}{$\begin{array}{c}\text { Solução inicial } \\
\text { Alíquotas do } \\
\text { modelo }\end{array}$} & \multirow{3}{*}{$\begin{array}{c}\text { Ajuste } \\
\text { exponencial } \\
\begin{array}{c}\text { Alíquotas do } \\
\text { ajuste }\end{array}\end{array}$} \\
\hline & \multicolumn{2}{|c|}{ Faixas valores venais (em $\mathrm{R} \$$ ) } & \multirow{2}{*}{$\begin{array}{l}\text { Qtde. } \\
\text { imóveis }\end{array}$} & \multirow{2}{*}{$\begin{array}{l}\text { Importe da faixa } \\
(\mathrm{em} \mathrm{R} \$)\end{array}$} & & \\
\hline & De & Até & & & & \\
\hline 1 & 0,00 & $10.156,00$ & 18.968 & $163.872 .789,54$ & $0,20000 \%$ & $0,23432 \%$ \\
\hline 2 & $10.156,01$ & $19.836,00$ & 49.316 & $688.069 .936,13$ & $0,25815 \%$ & $0,27717 \%$ \\
\hline 3 & $19.836,01$ & $30.994,00$ & 28.898 & $718.553 .383,10$ & $0,33043 \%$ & $0,32786 \%$ \\
\hline 4 & $30.994,01$ & $48.429,00$ & 28.012 & 1.097.098.264,09 & $0,41429 \%$ & $0,38781 \%$ \\
\hline 5 & $48.429,01$ & $75.670,00$ & 26.182 & $1.577 .427 .751,08$ & $0,51009 \%$ & $0,45873 \%$ \\
\hline 6 & $75.670,01$ & $118.234,00$ & 19.028 & $1.763 .806 .889,28$ & $0,60541 \%$ & $0,54261 \%$ \\
\hline 7 & $118.234,01$ & $184.741,00$ & 9.890 & $1.431 .874 .905,84$ & $0,69242 \%$ & 0,64183\% \\
\hline 8 & $184.741,01$ & $288.658,00$ & 4.344 & $981.222 .515,04$ & $0,79134 \%$ & $0,75920 \%$ \\
\hline 9 & $288.658,01$ & $451.028,00$ & 1.171 & $401.651 .868,46$ & $0,90439 \%$ & $0,89803 \%$ \\
\hline 10 & $451.028,01$ & $704.731,00$ & 257 & $136.545 .678,14$ & $1,03359 \%$ & $1,06225 \%$ \\
\hline 11 & $704.731,01$ & $1.101 .143,00$ & 39 & $35.539 .167,24$ & $1,18125 \%$ & $1,25649 \%$ \\
\hline \multirow[t]{4}{*}{12} & $1.101 .143,01$ & Ou maior & 3 & $6.026 .387,73$ & $1,35000 \%$ & $1,48626 \%$ \\
\hline & Tota & $s \Rightarrow$ & 186.108 & $9.001 .689 .535,67$ & $\mathrm{R} \$ 50.972 .425,89$ & $\mathrm{R} \$ 47.941 .644,01$ \\
\hline & \multicolumn{4}{|c|}{ Valor mínimo esperado para a arrecadação = } & $R \$ 50.616 .514,58$ & $\mathrm{R} \$ 50.616 .514,58$ \\
\hline & \multicolumn{4}{|c|}{ Incremento sobre o valor mínimo esperado = } & $\mathrm{R} \$ 355.911,31$ & $-R \$ 2.674 .870,57$ \\
\hline
\end{tabular}

Fonte: Elaboração própria com base nos resultados obtidos do modelo (2011).

Então, com a finalidade de se conseguir um resultado melhor no incremento da arrecadação sem prejuízo da justiça tributária, foi realizada uma análise de sensibilidade através da variação do parâmetro de forma $\Theta$, e obteve-se então a solução ótima (tabela 12). Deste modo, com o parâmetro $\Theta$ igual a 0,118 , foi atingido o melhor resultado do modelo de 12 alíquotas conciliando de forma ótima um incremento satisfatório da arrecadação (R\$ 796.139,41), cujo importe foi 2,24 vezes superior ao da solução inicial, com um conjunto de alíquotas progressivas, das quais as cinco primeiras apresentaram valores inferiores aos da solução inicial. Este resultado beneficia 151.376 contribuintes, que representam $81,34 \%$ do total.

É importante ainda salientar que todos os resultados obtidos da análise de sensibilidade que resultaram em incrementos na arrecadação acima de R $\$ 796.049,47$ (solução ótima) não foram aceitáveis do ponto de vista da justiça tributária, pois apresentaram valores mais elevados para as quatro primeiras alíquotas relativas aos imóveis de padrão construtivo mais simples, cujos valores venais eram menores ou iguais a $R \$ 48.429,00$ (cotação de 2008) e 
que pertencem a 125.194 contribuintes, os quais representam 67,27\% do total. Esses foram os casos em que o parâmetro de forma $\Theta$ variou nos intervalos 0,111 a 0,112, 0,114 a 0,117 e 0,121 a 0,122 , com incrementos respectivos na arrecadação de $R \$ 1.385 .690,00$, $R \$$ 1.187.906,00 e R\$ 825.512,00. E ainda quando o parâmetro $\Theta$ assumiu o valor 0,119 , com um incremento de $\mathrm{R} \$ 962.816,20$ (tabela 12 ).

Gráfico 1

Solução inicial do modelo de 12 alíquotas e o ajuste estatístico

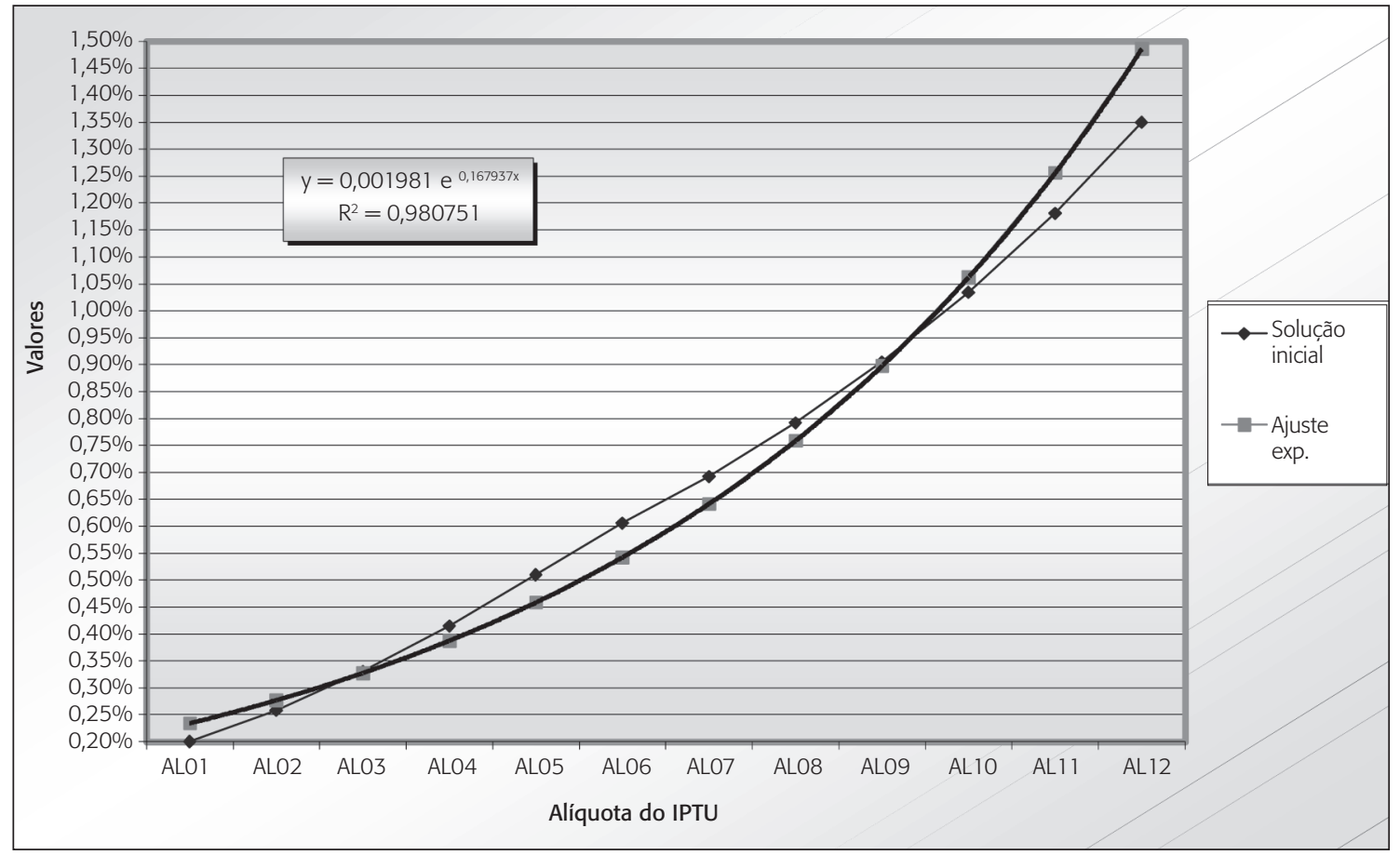

Fonte: Elaborado pelo autor com base nos dados obtidos da tabela 11 (2011).

Tabela 12

Resultados obtidos da Análise de Sensibilidade do modelo de 12 alíquotas

\begin{tabular}{|cccccc|}
\hline \multicolumn{2}{|c}{ Variação do $\Theta$} & & \multicolumn{2}{c|}{ Incremento na arrecadação (em R\$) } \\
\cline { 1 - 2 } \cline { 5 - 6 } De & Até & & \multicolumn{2}{c|}{ Variação } \\
\hline 0,001 & 0,043 & & $211.329,20$ & $213.961,90$ \\
0,044 & 0,069 & & $573.796,80$ & $575.468,60$ \\
0,070 & 0,086 & & $328.120,90$ & $329.302,90$ \\
\hline
\end{tabular}




\begin{tabular}{|c|c|c|c|}
\hline \multicolumn{2}{|c|}{ Variação do $\Theta$} & \multirow{2}{*}{\multicolumn{2}{|c|}{$\begin{array}{c}\text { Incremento na arrecadação (em R\$) } \\
\text { Variação }\end{array}$}} \\
\hline \multirow{2}{*}{$\frac{\mathrm{De}}{0,087}$} & \multirow{2}{*}{$\frac{\text { Até }}{0,089}$} & & \\
\hline & & $517.546,00$ & $517.637,70$ \\
\hline 0,090 & & $765.189,40$ & \\
\hline 0,091 & 0,104 & $286.023,90$ & $294.943,90$ \\
\hline 0,105 & & $53.417,57$ & \\
\hline 0,106 & 0,110 & $497.476,40$ & $497.881,90$ \\
\hline 0,111 & 0,112 & $1.385 .690,00$ & $1.385 .757,00$ \\
\hline 0,113 & & $302.188,80$ & \\
\hline 0,114 & 0,117 & $1.187 .906,00$ & $1.188 .077,00$ \\
\hline 0,118 & & $796.139,41$ & \\
\hline 0,119 & & $962.816,20$ & \\
\hline 0,120 & & $33.681,14$ & \\
\hline 0,121 & 0,122 & $825.431,90$ & $825.512,00$ \\
\hline 0,123 & 0,124 & $553.146,60$ & $553.200,10$ \\
\hline
\end{tabular}

Fonte: Elaborado pelo autor de acordo com os resultados da análise de sensibilidade do modelo (2011).

O resultado final, na forma de uma análise comparativa entre as soluções inicial e ótima do modelo de otimização (após análise de sensibilidade), está discriminado na tabela 13. Embora a solução ótima apresentada não tenha sido o melhor resultado do ponto de vista do incremento da arrecadação, torna o IPTU menos oneroso para as classes sociais dotadas de menor capacidade contributiva. Pode-se então deduzir que esse tipo de resultado poderá, provavelmente, além de melhorar a imagem do IPTU perante a sociedade, contribuir para a redução da sonegação e da evasão fiscal do imposto.

\section{Tabela 13}

Demonstrativo do resultado inicial e da solução ótima do modelo após análise de sensibilidade

\begin{tabular}{|c|c|c|c|c|c|c|}
\hline \multirow{3}{*}{$\begin{array}{c}\begin{array}{c}\text { Alíquotas } \\
\text { do IPTU }\end{array} \\
\text { № }\end{array}$} & \multicolumn{4}{|c|}{ Base de cálculo } & \multirow{3}{*}{$\begin{array}{c}\begin{array}{c}\text { Solução inicial do } \\
\text { modelo }\end{array} \\
\text { Alíquotas }\end{array}$} & \multirow{3}{*}{$\begin{array}{c}\begin{array}{c}\text { Solução ótima } \\
\text { pós-análise }\end{array} \\
\text { Alíquotas }\end{array}$} \\
\hline & \multicolumn{2}{|c|}{ Faixas valores venais (em $\mathrm{R} \$$ ) } & \multirow{2}{*}{$\begin{array}{l}\text { Qtde. } \\
\text { imóveis }\end{array}$} & \multirow[b]{2}{*}{ Importe da faixa } & & \\
\hline & $\mathrm{De}$ & Até & & & & \\
\hline 1 & 0,00 & $10.156,00$ & 18.968 & $163.872 .789,54$ & $0,20000 \%$ & $0,20000 \%$ \\
\hline 2 & $10.156,01$ & $19.836,00$ & 49.316 & $688.069 .936,13$ & $0,25815 \%$ & $0,25306 \%$ \\
\hline 3 & $19.836,01$ & $30.994,00$ & 28.898 & $718.553 .383,10$ & $0,33043 \%$ & $0,32021 \%$ \\
\hline 4 & $30.994,01$ & $48.429,00$ & 28.012 & 1.097.098.264,09 & $0,41429 \%$ & $0,40041 \%$ \\
\hline
\end{tabular}




\begin{tabular}{|c|c|c|c|c|c|c|}
\hline \multirow{3}{*}{$\begin{array}{c}\begin{array}{c}\text { Alíquotas } \\
\text { do IPTU }\end{array} \\
\text { № }\end{array}$} & \multicolumn{4}{|c|}{ Base de cálculo } & \multirow{3}{*}{$\begin{array}{c}\begin{array}{c}\text { Solução inicial do } \\
\text { modelo }\end{array} \\
\text { Alíquotas }\end{array}$} & \multirow{3}{*}{$\begin{array}{c}\begin{array}{c}\text { Solução ótima } \\
\text { pós-análise }\end{array} \\
\text { Alíquotas }\end{array}$} \\
\hline & \multicolumn{2}{|c|}{ Faixas valores venais (em $\mathrm{R} \$$ ) } & \multirow{2}{*}{$\begin{array}{c}\text { Qtde. } \\
\text { imóveis }\end{array}$} & \multirow[b]{2}{*}{ Importe da faixa } & & \\
\hline & $\mathrm{De}$ & Até & & & & \\
\hline 5 & $48.429,01$ & $75.670,00$ & 26.182 & $1.577 .427 .751,08$ & $0,51009 \%$ & $0,50068 \%$ \\
\hline 6 & $75.670,01$ & $118.234,00$ & 19.028 & $1.763 .806 .889,28$ & $0,60541 \%$ & $0,62594 \%$ \\
\hline 7 & $118.234,01$ & $184.741,00$ & 9.890 & $1.431 .874 .905,84$ & $0,69242 \%$ & $0,71096 \%$ \\
\hline 8 & $184.741,01$ & $288.658,00$ & 4.344 & $981.222 .515,04$ & $0,79134 \%$ & $0,80753 \%$ \\
\hline 9 & $288.658,01$ & $451.028,00$ & 1.171 & $401.651 .868,46$ & $0,90439 \%$ & $0,91722 \%$ \\
\hline 10 & $451.028,01$ & $704.731,00$ & 257 & $136.545 .678,14$ & $1,03359 \%$ & $1,04180 \%$ \\
\hline 11 & $704.731,01$ & $1.101 .143,00$ & 39 & $35.539 .167,24$ & $1,18125 \%$ & $1,18329 \%$ \\
\hline 12 & $1.101 .143,01$ & Ou maior & 3 & $6.026 .387,73$ & $1,35000 \%$ & $1,34160 \%$ \\
\hline & Tot & $s \Rightarrow$ & 186.108 & $9.001 .689 .535,67$ & $\mathrm{R} \$ 50.972 .425,89$ & $\mathrm{R} \$ 51.412 .653,99$ \\
\hline & & Valor mínin & esperado & para a arrecadação = & $R \$ 50.616 .514,58$ & $\mathrm{R} \$ 50.616 .514,58$ \\
\hline & & Incremento & obre o val & mínimo esperado $=$ & $R \$ 355.911,31$ & $\mathrm{R} \$ 796.139,41$ \\
\hline
\end{tabular}

Fonte: Elaboração própria com base nos resultados obtidos da análise de sensibilidade do modelo (2011).

Concluindo, vale ressaltar que as pesquisas e o estudo que resultaram nos modelos aqui apresentados podem ser considerados como o embrião de um trabalho bem mais abrangente. Espera-se, em uma perspectiva futura, o desenvolvimento de um novo modelo integrado para o IPTU envolvendo todos os tipos de imóveis, com uma configuração capaz de promover a preservação do meio ambiente, conciliar uma política de justiça tributária com o incremento da arrecadação, corrigir distorções e eliminar ou reduzir as subjetividades existentes na metodologia de cálculo do referido imposto, visando contribuir para uma melhor justiça social e maior sustentabilidade ambiental.

\section{Referências}

ABDALA, Demétrio C. Efeitos da receita orçamentária sobre o Índice de Desenvolvimento Humano (IDH): uma análise da realidade brasileira na década de 1990. Dissertação (mestrado) — Fundação Getulio Vargas do Rio de Janeiro, Rio de Janeiro, 2008.

ARENALES, Marcos et al. Pesquisa operacional. Rio de Janeiro: Campus, 2006.

ASSOCIAÇÃO BRASILEIRA DE EMPRESAS DE PESQUISA (Abep). Relatórios do Critério de Classificação Econômica do Brasil (CCEB). Disponível em: <www.abep.org/novo/Content.aspx? SectionID=84>. Acesso em: 5 set. 2009. 
BAHIA. Código Tributário e de Rendas do Município de Salvador (CTRMS), Lei no 7.186, de 27 de dezembro de 2006. Salvador: Prefeitura Municipal. 2006. Institui o Código Tributário e de Rendas do Município de Salvador. Disponível em: <www.sefaz.salvador.ba.gov.br/sistema/legislacao/tabelas anexas/anexos/CTRMS-Alt.7.611-08, 7.727-09 e 7.952-10.pdf>. Acesso em: 15 dez. 2009.

BAHIA. Decreto Municipal 19.223 de 29 de dezembro de 2008. Salvador: Prefeitura Municipal. 2008. Fixa Valores Unitários Padrão - VUP de terrenos e de edificações, atualiza os valores que indica, para efeito de avaliação de unidade imobiliária e lançamento do IPTU, e da Taxa de Coleta, Remoção e Destinação de Resíduos Sólidos Domiciliares - TRSD, para o exercício de 2009, e dá outras providências. Disponível em: <www.sefaz.salvador.ba.gov.br/index.php/decretos>. Acesso em: 15 dez. 2009.

BAHIA. Decreto Municipal no 14.116 de 27 de dezembro de 2002. Salvador: Prefeitura Municipal. 2002. Fixa Valores Unitários Padrão (VUP) de terrenos, atualiza os valores que indica, para efeito de avaliação de unidade imobiliária e lançamento do IPTU, e de lançamento da Taxa de Limpeza Pública (TL), do exercício de 2003, e acrescenta parágrafos ao art. 4 do Decreto no 9.207, de 11 de novembro de 1991. Disponível em: <www.sefaz.salvador.ba.gov.br/index.php/decretos>. Acesso em: 15 dez. 2009.

BAHIA. Decreto Municipal no 9.207 de 11 de novembro de 1991. Salvador: Prefeitura Municipal. 1991. Dispõe sobre os elementos para a fixação da base de cálculo de terrenos e edificações e para fatores de valorização, desvalorização e avaliação especial de unidades imobiliárias. Disponível em: <www.sefaz.salvador.ba.gov.br/index.php/decretos>. Acesso em: 15 dez. 2009.

BALLARINI, Sérgio D. IPTU progressivo causa dano moral coletivo ambiental. São Paulo: Suprema, 2010.

BARBOSA, Evandro P. Progressividade do IPTU. São Paulo: Pillares, 2007.

BAZARAA, Mokhtar et al. Nonlinear programming. Nova York: John Wiley, 2006.

BONETTI, Maria J. Da progressividade nos impostos. Dissertação (mestrado) — Pontifícia Universidade Católica de São Paulo, São Paulo, 1997.

BOQUIMPANI, Eduardo G. Estado, ambiente, justiça fiscal e tributação: a progressividade do IPTU. Tese (doutorado) — Universidade do Estado do Rio de Janeiro, Rio de Janeiro, 2007.

BRASIL. Constituição (1988). Constituição da República Federativa do Brasil. 3. ed. São Paulo: Atlas, 1993.

BRASIL. Estatuto da Cidade, Lei no 10.257 de 10 de julho 2001. Regulamenta os arts. 182 e 183 da Constituição Federal, estabelece diretrizes gerais da política urbana e dá outras providências. Disponível em: <www.planalto.gov.br/ccivil_03/leis/leis_2001/110257.htm>. Acesso em: 15 out. 2010.

BRASIL. Poder Executivo. Código Tributário Nacional (CTN), Lei no 5.172 de 25 de outubro de 1966. 22. ed. São Paulo: Saraiva, 1990.

BUCHER, Hildomar H. A função social da propriedade e a progressividade do IPTU. Dissertação (mestrado) — Pontifícia Universidade Católica de São Paulo, São Paulo, 1996. 
CAMARGO, Juliana W. O IPTU como instrumento de atuação urbanística. Belo Horizonte: Fórum, 2008.

CARRAZZA, Elizabeth N. Os princípios da igualdade e da capacidade contributiva e a progressividade do IPTU. Tese (Doutorado) — Pontifícia Universidade Católica de São Paulo, São Paulo, 1992.

CARVALHO JR., Pedro H. B. IPTU no Brasil: progressividade, arrecadação e aspectos extrafiscais. Brasília, DF: Ipea, dez. 2006. (Texto para Discussão no 1.251). Disponível em: <www.ipea.gov. br/agencia/images/stories/PDFs/TDs/td_1251.pdf>. Acesso em: 30 jan. 2009.

COLIN, Emerson C. Pesquisa operacional - 170 aplicações em estratégia, finanças, logística, produção, marketing e vendas. Rio de Janeiro: LTC, 2007.

DE CESARE, Claudia M. IPTU: otimização \& justiça tributária. In: CURSO DE GESTÃO URBANA E DE CIDADES, 4, 2002, Belo Horizonte. Anais eletrônicos. Escola de Governo da Fundação João Pinheiro, 2002. Disponível em: <www.eg.fjp.mg.gov.br/gestaourbana/arquivos/modulo09/Iptu_ CMDeCesare.doc>. Acesso em: 14 out. 2010.

DHAMI, Sanjit; AL-NOWAIHI, Ali. Optimal taxation in the presence of tax evasion. Journal Economic Behavior \& Organization, v. 75, p. 313-337, 2010.

FERNANDES, Cíntia E. IPTU: texto e contexto. São Paulo: Quartier Latin, 2005.

FRAGA, Henrique R. O Imposto Predial e Territorial Urbano (IPTU) e o princípio da progressividade. São Paulo: IOB, 2007.

FURLAN, Valéria C. P. IPTU. 2. ed. São Paulo: Malheiros, 2004.

GARSON, Sol. O IPTU como instrumento de política pública no contexto da lei de responsabilidade fiscal. In: CURSO DE GESTÃO URBANA E DE CIDADES, 2001, Belo Horizonte. Anais eletrônicos. Escola de Governo da Fundação João Pinheiro, 2001. Disponível em:<www.fjp.gov.br/index.php/ institucional/266-eg >. Acesso em: 13 out. 2010.

HILLIER, Frederick S.; LIEBERMAN, Gerald J. Introduction to operations research. 8. ed. Nova York: McGraw-Hill, 2005.

IBGE. Pesquisa de orçamentos familiares (2002/2003). Rio de Janeiro: Editora IBGE, 2007.

INSTITUTO BRASILEIRO DE GEOGRAFIA E ESTATÍSTICA (IBGE). Disponível em: <www.ibge. gov.br/home >. Acesso em: 14 mar. 2009.

OLIVEIRA, José J. M. Impostos municipais: ISS, ITBI, IPTU. São Paulo: Saraiva, 2009.

PALERMO, Paulo S. G. O princípio da capacidade contributiva e o Imposto Predial e Territorial Urbano (IPTU) à luz da Constituição Federal de 1994. Dissertação (mestrado) — Fundação Getulio Vargas de São Paulo, São Paulo, 2005.

PAYERAS, José A. P. A carga tributária no Brasil e sua distribuição. Tese (doutorado) - Escola Superior de Agricultura Luiz de Queiroz, Universidade de São Paulo, Piracicaba, 2008.

PELEGRINA, Marco A. Diagnóstico para gestão do Imposto Predial e Territorial Urbano. Tese (doutorado) — Universidade Federal de Santa Catarina, Florianópolis, 2009. 
PREFEITURA MUNICIPAL DE BELO HORIZONTE. Secretaria de Finanças. Disponível em: < http:// portalpbh.pbh.gov.br/pbh/ecp/comunidade.do? evento $=$ portlet\&pIdPlc $=$ ecpTaxonomiaMenuPort al\&app $=$ iptu2012\&tax $=26558 \& l a n g=$ pt_BR\&pg $=9762 \& \operatorname{taxp}=0 \&>$. Acesso em: 10 set. 2010.

PREFEITURA MUNICIPAL DE CURITIBA. Secretaria de Finanças. Disponível em: <www.curitiba. pr.gov.br/conteudo/iptu-tabela-secretaria-municipal-de-financas/368 > . Acesso em: 10 set. 2010.

PREFEITURA MUNICIPAL DE FORTALEZA. Secretaria de Finanças - Sefin. Disponível em: <www. sefin.fortaleza.ce.gov.br/tributos_municipais/gerados/iptu.asp>. Acesso em: 10 set. 2010.

PREFEITURA MUNICIPAL DE PORTO ALEGRE. Secretaria da Fazenda. Disponível em: < www2. portoalegre.rs.gov.br/smf/default.php?p_secao=165>. Acesso em: 10 set. 2010.

PREFEITURA MUNICIPAL DE SALVADOR. Secretaria da Fazenda — Sefaz. Disponível em: <www. sefaz.salvador.ba.gov.br/sistema/index.htm >. Acesso em: 10 set. 2010.

PREFEITURA MUNICIPAL DO RECIFE. Secretaria de Finanças. Disponível em: <www2.recife. pe.gov.br/pcrservicos/imovel-iptu-taxas/>. Acesso em: 10 set. 2010.

SHAN, Hui. Property taxes and elderly mobility. Journal of Urban Economics, v. 67, n. 2, p. 194205, 2010.

VASQUES, Marcos Barbosa. IPTU: teoria geral do garantismo. Curitiba: Juruá, 2009.

\section{Apêndice A}

A Arrecadação Global do IPTU do município de Salvador, em 2009, era calculada através da seguinte formulação:

$$
A G=\sum_{i=1}^{m} \sum_{j=1}^{n} \sum_{k=1}^{Q \text { Il ij }}[(A l i j . V P \text { ijk })+(A T \text {. VE ijk })] \text {. FC ijk }
$$

Em que:

จ AG = Arrecadação Global do IPTU.

、 AI i j = Alíquota referente ao imóvel do Tipo i e Padrão Construtivo j.

- $\mathbf{A T}=$ Alíquota de Terreno sem Edificações.

v VP i j k = Valor Venal Principal do imóvel k, do Tipo i e Padrão Construtivo j.

、 VE i j k = Valor Venal Excedente do imóvel $\mathbf{k}$ do Tipo i e Padrão Construtivo $\mathbf{j}$.

v FC i j k = Fator de Correção do imóvel k do Tipo i e Padrão Construtivo j.

$\mathbf{v}=$ Importe dos Tipos de imóveis.

v $\mathbf{n}=$ Importe de Padrões Construtivos. 
、 QI i j = Quantidade de unidades imobiliárias do Tipo i e Padrão Construtivo j.

Fonte: A expressão matemática mostrada acima foi elaborada pelos autores com base nas informações fornecidas pela Sefaz-PMS.

\section{Apêndice B}

O modelo de otimização para $\mathbf{n}$ alíquotas, desenvolvido para o IPTU do município de Salvador, é descrito através das seguintes expressões matemáticas:

$$
\begin{aligned}
& \text { Maximizar } \Delta=X n-X 1 \\
& X
\end{aligned}
$$

Sujeito às seguintes restrições:

Definição dos limites das alíquotas mínima e máxima:

$\checkmark \mathrm{X} 1 \geq 0.0020$

$\checkmark \mathrm{Xn} \leq 0.0135$

Cálculo dos valores das alíquotas:

$\boldsymbol{V} \mathrm{Xi} \leq(1-\Theta) \cdot \mathrm{Xi}+1$

$\{\mathrm{i}=1,2, \ldots, \mathrm{n}-1\}$

$\nabla \mathrm{Xn} \geq(1+\Theta) \cdot 0.012$

$\nabla \Theta>0$;

$\boldsymbol{\nabla} \Theta \leq 1$

Hierarquização das alíquotas:

$\boldsymbol{\nabla} \mathrm{Xi}<\mathrm{Xi}+1$

$$
\{\mathrm{i}=1,2, \ldots, \mathrm{n}-1\}
$$

Determinação de incrementos proporcionais entre as alíquotas:

$\checkmark \mathrm{Xi}+1 / \mathrm{Xi}+2 \geq \mathrm{Xi} / \mathrm{Xi}+1$

$$
\{\mathrm{i}=1,2, \ldots, \mathrm{n}-2\}
$$

Cálculo do IPTU para os imóveis residenciais: 
$\boldsymbol{\nabla} \dot{\mathrm{I}}=\sum_{\mathrm{i}=1}^{\mathbf{n}} \mathrm{Xi} . \delta_{\mathrm{i}} . \Omega \quad\{\mathrm{i}=1,2, \ldots, \mathrm{n}\}$;

Limitação do incremento da arrecadação diante de um valor mínimo esperado:

$\checkmark \mathrm{I} \geq \Pi$

Em que:

- $\Delta$ = Diferença entre as alíquotas limites máxima e mínima;

Xi = Variáveis de decisão (alíquotas);

v $\Theta$ = Parâmetro de forma do modelo;

、 $\dot{\mathrm{I}}$ = Arrecadação total do IPTU dos imóveis residenciais (apartamentos);

$\checkmark \delta \mathrm{i}=$ Percentual referente ao valor da base de cálculo da Faixa i;

$\checkmark$ ' $\Omega$ = Valor total dos valores venais relativos à base de cálculo dos imóveis residenciais (apartamentos);

、 $\Pi$ = Valor referenciado como a arrecadação mínima aceitável para o IPTU;

$\checkmark \mathrm{n}=$ Número total de alíquotas.

José Delfino Sá é professor assistente da Universidade do Estado da Bahia (Uneb) e doutorando em engenharia industrial no Programa de Pós-Graduação em Engenharia Industrial da Escola Politécnica da Universidade Federal da Bahia (Ufba).E-mail: jdelsa2@yahoo.com.br.

Carlos Arthur Mattos Teixeira Cavalcante é professor associado II da Escola Politécnica da Ufba. E-mail: arthurtc@ufba.br.

Ricardo de Araújo Kalid é professor associado II da Escola Politécnica da Ufba. E-mail: kalid@ufba.br.

Ulisses de Araújo Malveira é coordenador da Controladoria de Tributos Imobiliários (CTI) da Secretaria da Fazenda da Prefeitura Municipal de Salvador (Sefaz-PMS). E-mail: uamalveira@sefaz.salvador. ba.gov.br. 